\title{
Social impact of epilepsy on life of people with epilepsy: An ethnographic evaluation
}

\author{
Neha Wasal
}

Author for Correspondence :

\section{Neha Wasal}

Arya College, Ludhiana (Punjab) India

Email : neha_wasal@yahoo.com

Received: 09.10.2020; Revised: 09.11.2020; Accepted: 26.11 .2020

ABSTRACT : Epilepsy is considered as a stigma in our society, and PWE's have to face many social issues. This becomes more prominent among those who are in marriageable age. In this paper21 PWE were interviewed who attended an outpatient epilepsy clinic at a secondary-level hospital in Northwest India between 01.01.2015 and 31.03.2015 formed the case material for this study. Some cases were deeply interrogated and it was found that all of them faced certain kind of social problems while suffering from epilepsy. Half of respondentssaid that main social problem faced by them was related to marriage. Many of the epilepsy patient denied the fact of having epilepsy with their future partner . They also denied of revealing them about taking ADE'S. it was found that PWE's face many social and psychological problems while marriage negotiations and even after marriage.

KEY WORDS: Nutrimix, Diabetes, Supplementation, Blood Gluose Levels

- HOW TO CITE THIS PAPER : Wasal, Neha (2020). Social impact of epilepsy on life of people with epilepsy: An ethnographic evaluation. Asian J. Home Sci., 15 (2) : 387-392, DOI: 10.15740/HAS/AJHS/ 15.2/387-392. Copyright@2020: Hind Agri-Horticultural Society. 
Sociologically, the marriage whether is arranged by others or chosen for love by the individuals to be wedded, marriage is a structured and has patterned set of social relations and practices. It is embedded in norms and values regarding what marriage should be and is. There are explicit social prescriptions and sanctions by public bodies, the state, religion and community (Kaur and Palriwala, 2014).

\section{— RESEARCH METHODS}

21 PWE who attended an outpatient epilepsy clinic at a secondary-level hospital in Northwest India between 01.01.2015 and 31.03.2015 formed the case material for this study. Their conversation were recorded with their consent. Tape-recorded conversations in native language (Hindi or Punjabi) were transcribed and subsequently translated to English language for discussion among, and analysis by experts. The written transcripts as well as tape-recorded conversations were presented at a one day, round-table meeting of epilepsy experts, neuropsychologists, a sociologist and a legal expert. The opinion of the experts and discussions thereof were also recorded and reviewed in preparation of this manuscript. The consensus opinion of the experts is rendered in this manuscript. Four conversations touching upon marital design or experiences in PWE are presented here for their representativeness.

Conclusions of this study is based upon issues which were highlighted during the conversation with PWE. Based on these communications some social impact of epilepsy was analysed.

\section{Impact on the personality:}

A person's body is an integral part of their self esteemand identity. If one organ of the body doesn't work properly, then it affects the whole personality. Especially if the brain does not function as others' brains do forces the person to think that he/she is lower than others in certain manner. The adolescent's question "Who am I?" recurs, which can be traumatic for an adult. Lower self-esteem can result from perception of the self as less competent than others and self-categorisation as an "epileptic" and consequent perception of stigma for the patient. Diagnosis can result in many psychological difficulties. The PWE's may feel grief at the realisation of being disabled goes through stages of shock, anxiety, bargaining and denial, mourning and depression, internalised anger, externalised anger, acknowledgement and finally acceptance and adjustment.

This kind of grief can occur either at onset or on realisation of difference. Reversion of grief possible at any time. Many other emotional states which may recur include anxiety arising from the unpredictability of seizures and feelings of lack of control and helplessness. Guilt can result in affective disorder. Anxiety combined with guilt can also become depression in certain cases. Lowered energy and vitality may also result from disrupted sleep patterns, on the other side defensiveness can lead to a need to conceal, anger and hatred. Epilepsy is a "hidden" or "invisible" disability, which occurs suddenly as no symptoms are apparent except during a seizure. It often has no major cause, which results in a fear of the unknown. This is the major problem for PWE's as they are confused about their health and personality. Consequently it is easier to deny, resulting in poor compliance with treatment and a refusal to alter lifestyle because of epilepsy. Being "hidden" makes it more difficult for others with whom they wish to interact, and concealment makes it difficult to find other people with epilepsy for support. Being "hidden" may lead to accusations of hypochondria and misbehaviour as well as erroneous self-perception.

\section{Impact of the family :}

Diagnosis of epilepsy in their child leads to stress and pain in parents, resulting in a higher divorce rate. Focus by parents on the child with epilepsy can result in poor relationships between the child with epilepsy and siblings and psychological difficulties among siblings. It may also cause over protection for child which creates a barrier for the development of child. Such focus can also affect family cohesion and relations between the family and their community. PWE's become burden for the family as someone needs to be with them all the time for their security. This feeling creates frustration among the child with epilepsy. It can result in the people with epilepsy growing up to make a poor parent themselves.

\section{Impact on education:}

People in India considers epilepsy as a Stigma. This social perception makes life hell for the PWE's. usually in country like India, PWE's are not allowed to take education. A higher prevalence is found in people with epilepsy of learning disabilities and memory problems, 
often caused by co-morbidities such as brain damage. Attention deficits occur during seizures, especially during absence seizures in schoolchildren. Antiepileptic drug side-effects of drowsiness and short attention span can affect educational achievement and are commonly exacerbated by polytherapy. Even if the PWE doesn't have these symptoms, parents don't allow their child to go to school or college alone. They are afraid of the revealing of their children's epilepsy. Because in India people starts discriminating with PWE's.

\section{Impact on employment :}

While going for employment, PWE's get lesser chances in compare to other people. This is again due to some misunderstandings related to epilepsy. Unemployment is higher among people with epilepsy, by up to $50 \%$ in developed countries if Neurology Asia 2007; 12 (Supplement 1) : $10-1211$ seizures are not fully controlled and up to $100 \%$ in developing countries. This can be caused by employer prejudice resulting from stigma and a lack of information, a belief that machinery should be avoided by the people with epilepsy, inability to drive, or poorer academic achievement. Disclosure to an employer is therefore a difficult decision and usually people hide the fact of having epilepsy. Unemployment also creates low self esteem among the PWE's. Unemployment commonly results in a lower SES, lower self-esteem, lessened well-being and a lower quality of life.

\section{Impact on social relationships:}

Social isolation and poor social adaptation can result from perceived stigma or over-dependency caused by parental overprotection of the PWE's. The people with epilepsy also often fears embarrassment by a seizure, which causes reluctance to engage in social interaction and social participation, with concomitantly low selfesteem and academic under-achievement. These can result in a shrunken social network, fewer friends, a lower likelihood of marriage and greater likelihood of anti-social behaviour. Most of the PWE'S tend to become introvert because of they always try to hide their weakness in front of others.

\section{Impact on sexual relationships:}

Satisfactory relations with the sex partner requires good self-esteem. Low self-esteem in a people with epilepsy can result in failure to establish good sexual relationships. AED (Anti Epileptic Drug) may also result in anhedonia. Head injury may result in reduced libido and erectile dysfunction. Inadequate sexual functioning may result in depression, marital distress or selfaversion.in certain cases PWE'S also find it difficult to find right partner for marriage. As there are more chances of rejection for the PWE's.

\section{Impact on women :}

Epilepsy causes unique problems for women. Especially in Indian society where place of women is not that good in comparison to man. Seizure frequency and severity can be exacerbated by menstrual hormonal changes. Women with epilepsy often experience anxieties concerning children. Doubts about seizures being triggered by labour, their ability to care for their child, the possibility of inheritance of epilepsy and birth defects are compounded by fears about antiepileptic drug side effects and the mother's ability to be a good role model during childrearing. The biggest social problem women with epilepsy face is the problem of rejection from society. Other major social problem being faced by women is the lack of education and opportunities.

\section{Impact on quality of life:}

Quality of life is “the degree to which a person's cognitive, emotional, social and spiritual experience of life is positive". Quality of life for a people with epilepsy can be reduced by higher physical morbidity rates, seizure-related accidents, antiepileptic drug side effects, more social withdrawal, increased social isolation, poorer sexual relationships, and lower marriage rates. Quality of life for the people with epilepsy may also be reduced by higher psychological morbidity rates, anxiety and depression, lower self-esteem, increased helplessness, defensive aggressiveness, poorer educational achievement and higher unemployment or underemployment. 12 SOLUTIONS To cope with epilepsy, the people with epilepsy needs information and psychological and social support. The physician can supply some of each, but not as much as is needed, nor for the weeks, months and years over which they are needed. The physician should therefore refer a people with epilepsy to an epilepsy specialist nurse, a psychologist a psychiatrist or an epilepsy specialist community worker. The epilepsy specialist community worker can provide 
support, be an informed, empathetic listener, alleviate fear of the unknown, encourage compliance, and provide information to the people with epilepsy, their family and the community. The epilepsy specialist community worker can also facilitate the establishment of contacts and selfhelp groups to boost self-esteem and confidence. Moreover the epilepsy specialist community worker can provide information about epilepsy, available drugs, alternative approaches to control, the local medical scene, benefits and other available assistance and employment. The epilepsy specialist community worker can also help the people with epilepsy in thinking about whether or not to disclose, local regulations for driving, insurance, and in contacting other people with epilepsy. They can advocate, assist the people with epilepsy to communicate with the clinician and train the patient in reporting seizure activity and drug efficacy and side effects. The epilepsy specialist community worker can follow up clinical advice to ensure compliance and assist in communicating with employers, officials and others having power in the life of the people with epilepsy, such as members of the family

\section{- RESEARCH FINDINGS AND DISCUSSION}

Four PWE's were studied deeply for this research paper. The patients were selected on the basis of their age group. Those cases were in marriageable age. Because people in this age tend to have more social relationship and they deal with society on regular basis. Results found that lack of support from the family was major problem faced by them. On the other hand lack of education was another major social issue related to PWE'S. their right to education gets disturbed because of epilepsy. Some of the respondents that they were socially boycott by other people. In majority of cases seizures were controlled while taking AED's majority of them were about to get married in coming time Results showed that all four PWE's denied torevealthe factof having epilepsy to their would be in laws and perspective life partners. Two of them also denied to reveal about taking AED's to their partners and their families. Both of them and their families were afraid of cancellation of engagement if they reveal the epilepsy fact. This shows the level of stigma attached with epilepsy in Indian society. The conversations depicted that in most of the cases people tend to hide the fact of epilepsy as the breakdown of matrimonial negotiations becomes main cause for families of PWE to hide epilepsy in arranged marriage. Hiding the fact of having epilepsy not only exist in marriage negotiations, but PWE also hide it in a range of social interactions like within kinship, in workplace, in peer groups, strangers and even in intimate relationships.

\section{Marriage and Epilepsy:}

Practices, customs, rituals and attitudes towards marriage vary considerably from one region to another and these variations need to be factored in consideration of the impact of epilepsy on marriage. A distinctive tradition, the arranged marriage is widespread in much of South Asia but also observed in smaller numbers in the rest of the world. Over $95 \%$ of those who get married in India, Pakistan and Bangladesh and over $50 \%$ of those in Sri Lanka aside from the enormous expatriate populations from these countries in Western as well as Arabian countries do so by way of arranged marriages. Arranged marriage is defined as one where parents choose marital partners for their children and arranged marriage is a norm in many parts of Asia, Africa and Middle East On the other hand, non arranged marriages are common in the Western part of the world. In the modern world there is co-existence of both types of marriage system.

The stigma attached to epilepsy becomes more pronounced, especially when it comes for marriage; even though the word epilepsy has been removed from the Hindu Marriage Act 1955 and Special Marriage Act long ago. In a study it was reported a lower marriage rate, delayed marriage especially among females, suspended marriage, and higher divorce rate in PWE as compared to general population. The disease status of PWE is usually not disclosed in most of India at the time of marriage due to fear of failure of marriage negotiations (Aggarwal et al.,).it was observed that nearly 55\% of people with epilepsy have concealed their disease status at the time of marriage. There was an increased demand for dowry or cancellation of engagements following disclosure (Santosh et al.).

Marital disharmony ensues when the presence of epilepsy becomes evident. Among those who concealed their epilepsy status at the time of marriage; $18 \%$ were divorced, $20 \%$ were separated, and $45 \%$ were disturbed. have reported adverse treatment outcome due to marital disharmony among the PWE. Due to the long fought battle of Indian Epilepsy Association (IEA), the Indian 
judiciary has in recent times pronounced that epilepsy should not be equated to mental illness and the practice of divorce among married individuals due to epilepsy should be strongly discouraged (Das et al.,).

\section{Hiding or revealing the fact of epilepsy:}

Patients with epilepsy who entered in marriageable age tend to feel more pressure and depression in traditional societies because of not fulfilling the social aspirations of his/her society have more depression.

Except when epilepsy is either severe or associated with psychiatric comorbidity or neurological handicap, the disorder is concealable. Other than during brief periods of seizures or convulsive activity, it goes unnoticed and in this manner, it is different from physical disorders, e.g., limb disability. This feature is permissive to hiding epilepsy during marital negotiations in arranged marriages. There are certain factors responsible which forces PWE not to reveal the fact like: 1) less social acceptability of PWE's, 2) unawareness among the people regarding epilepsy, 3) social stigma attached with epilepsy, 4) social rejection towards PWE. The family seems to have already considered the advantages and risks of hiding epilepsy during the marital negotiations and the consequences thereof while at the same time appear to have an understanding of the implication of stopping epilepsy medications for the fear of revelation after marriage. It might be pertinent to point out the potential consequences of hiding epilepsy during marital negotiations in arranged marriages. While divorce rates are comparatively low in arranged marriages, the likelihood of PWE divorcing increases in arranged marriages in comparison to love marriages. In these arranged marriages, divorce is associated with hiding epilepsy during marital negotiations.

As far as the hiding the fact in marriage negotiation is concerned, there are certain causes behind it. Like in traditional societies, people are very protective about their children's life. No parent wants their children to marry a person who himself/herself is living with some uncertainty. Especially in arranged marriage, where the total responsibility of getting the child married to a good person is on parents. Families in traditional societies are society driven families. Where people care more about their social status rather taking care of individual.

In these societies, parents of PWE hide the fact of epilepsy as they also feel social pressure of getting their child married. But this cannot happen if they reveal the epilepsy fact. Another unawareness about epilepsy in these societies are less productivity of PWE and becomes a burden on the family, as earning opportunities and education attaining chances gets limited for PWE's

\section{Bearing expenses of medication:}

In many cases of married women with epilepsy, taking medicine after marriage becomes a major issue of concern as they concealed the fact of having epilepsy at the time of marriage. Sometimes, married women stop taking medicine after marriage due to many factors. In some cases, many subjects keep on taking medicine without telling the partner and in those cases, it was the natal family of the women with epilepsy rather than the conjugal family that bore the responsibility as well as expenses of treatment. While, in many cases hiding epilepsy in married life might lead to PWE either discontinuing their epilepsy medications only to have seizures or continuing to use medications in a surreptitious manner. Even so, hiding epilepsy might conceivably be a barrier to visit specialist or other health-care providers at a time after marriage when specialist advice is much needed, e.g., regarding contraception, pregnancy planning and monitoring medications during pregnancy. This is clearly illustrated in some subjects, who would have recourse to medical consultation only while visiting their natal homes. Besides, hiding epilepsy has been associated with a poor marital outcome.

\section{Reproductive issues and epilepsy:}

Issues regarding reproduction is a major concern in WWE. For females, the issues of child-bearing and childrearing and for the male the issues of employment and income have become critical during the marriage.It is always said that a healthy mother can give birth to healthy child. Pregnancy after marriage was discouraged due to fear of having a child with epilepsy or other abnormalities. Earlier studies have indicated that WWE have reduced fertility. For females, the issues of childbearing and child-rearing and for the male the issues of employment and income have become critical during the marriage. A study by Agarwal et al., reported a lower marriage rate, delayed marriage especially among females, suspended marriage, and higher divorce rate in PWE as compared to general population. The disease status of PWE is usually not disclosed in most of India 
at the time of marriage due to fear of failure of marriage negotiations. Santosh et al. observed that nearly $55 \%$ of people with epilepsy have concealed their disease status at the time of marriage. There was an increased demand for dowry or cancellation of engagements following disclosure.

\section{Conclusion:}

In conclusion, poor marital prospect and high divorce rate of PWE in many Asian countries reflect the effects of social stigma and many other adverse factors that the PWE have to face, although there are already progresses in some societies. Lack of education, lack of opportunities and social discrimination are some of major social issues beieng faced by PWE'S. To maintain a balance between marriage and epilepsy, thepeople with epilepsy need information and psychological and social support. This awareness regarding epilepsy can be provided through the support of epilepsy specialist community worker , who can beinformed, empathetic listener, alleviate fear of the unknown, encourage compliance, and provide information to the people with epilepsy, their family and the community. The epilepsy specialist community worker can also facilitate the establishment of contacts and selfhelp groups to boost self-esteem and confidence. Moreoverthe epilepsy specialist community worker can provide right information about epilepsy, and how to maintain a balance between married life and epilepsy. The epilepsy specialist community worker can also help the people with epilepsy in thinking about whether or not to disclose, local regulations for driving, insurance, and in contacting other people with epilepsy. Moreover, one needs to educate the family of PWE regarding epilepsy, they should motivate the PWE's to empower themselves with other aspects of life.

\section{REFERENCES}

Aggarwal, A., Datta, V. and Thakur, L.C. (2011). Quality of life in children with epilepsy. Indian Pediatr., 48 : 893-896.

Akriti Gupta, Jasneet Singh Chawla, Karan Saggar, Praneet Wander, Hitant Vohra, R.K. Bansal, Caroline Selai and Gagandeep Singh (2016). Arranged Marriagesin People with Epilepsy: A Pilot Knowledge, Attitudes and Practices Survey from India. 2016. Epilepsy and Brain.

Banerji, M. (2008). Is Education Associated with a transition towards autonomy in partner choice? A case study of India.New Delhi.
Das, K., Banerjee, M., Mondal, G.P., Devi, L.G., Singh, O.P. and Mukherjee, B.B. (2007). Evaluation of socio-economic factors causing discontinuation of epilepsy treatment resulting in seizure recurrence: A study in an urban epilepsy clinic in India. Seizure, 16: 601-607.

Gabriela, R. (2014). The love revolution: Decline in arranged marriage in Asia, the Middle East and Sub-Saharan Africa. University of California, Los Angeles.

Gopinath, M., Sarma, P.S. and Thomas, S.V. (2011). Genderspecific psychosocial outcome for women with epilepsy. Epilepsy Behav., 20 : 44-47.

Jacoby, A. (2002). Stigma, epilepsy, and quality of life. Epilepsy Behav., 3 : 10-20.

Kaur, R. and Palriwala, R. (2014). Marrying in South AsiaShifting Concepts, Changing Practices in the Globalizing World Orient Blackswan Private Limited. New Delhi, India.

Marriot, M. (1990). Introduction. In, India through Hindu categories, Ed. Marriott, McKim..Sage Publishers. London.

Santosh, D., Kumar, T.S., Sarma, P.S. and Radhakrishnan, K. (2007). Women with onset of epilepsy prior to marriage: Disclose or conceal? Epilepsia, 48 : 1007-1010.

Santosh, D., Kumar, T.S., Sarma, P.S. et al. (2007). Women with onset of epilepsy prior to marriage: disclose or conceal? Epilepsia, 48 : 1007-1010.

Senthil Amudhan, Gopalkrishna Gururaj and Parthasarathy Satishchandra (2015). Epilepsy in India II: Impact, burden, and need for a multisectoral public health response. Ann. Indian Academy Neurol., 18(4): 369-381.

Singh, Gagandeep, Pauranik, Apoorva, Menon, Bindu, Birinder S. Paul, Caroline Selai, Debashish Chowdhury, Deepak Goel, H.V.Srinivas, Hitant Vohra, John Duncan, Kalyani Khona, Manish Modi, Man Mohan Mehndiratta, Parampreet Kharbanda, Parveen Goel, Pravina Shah, Rajinder Bansal, Renu Addlakha, Sanjeev Thomas, Satish Jain, Urvashi Shah, V.S.Saxena, Veena Sharma, V.V.Nadkarni and Yashoda Wakankar (2016). The dilemma of arranged marriages in people with epilepsy. An expert group appraisal.

Troster, H. (1997). Disclose or conceal? Strategies of information management in persons with epilepsy. Epilepsia, 38:1227-1237.

Xu Xiaohe MKW (1990). Love Matches and Arranged Marriages: A Chinese Replication. J. Marriage \& Family, 52 : 709-722.

Senthil Amudhan, Gopalkrishna Gururaj, Parthasarathy Satishchandra (2017). Epilepsy in India II: Impact, burden, and need for a multisectoral public health response. http:// www.annalsofian.org on Thursday, August 17, 2017. 